\title{
Effect of Biologic Treatments on Growth in Children with Juvenile Idiopathic Arthritis
}

\author{
Florence Uettwiller, Julie Perlbarg, Graziella Pinto, Brigitte Bader-Meunier, Richard Mouy, \\ Sandrine Compeyrot-Lacassagne, Isabelle Melki, Carine Wouters, Anne-Marie Prieur, \\ Paul Landais, Michel Polak, and Pierre Quartier
}

\begin{abstract}
Objective. Growth retardation is a frequent complication of severe juvenile idiopathic arthritis (JIA). Biologic treatments may improve growth velocity by controlling systemic inflammation and reducing corticosteroids. Our goals were to compare growth velocity before and after the onset of biologic therapy and to determine whether the JIA subtype, the use of steroids, the requirement of one or several biologic agents, or the disease activity influenced growth velocity.

Methods. We retrospectively analyzed the growth of children with JIA who never received growth hormone treatment, who started biologic treatment before puberty, and who were followed for at least 6 months afterward.

Results. We included 100 children (33 boys). Median patient age was 7.1 years (range: 1.6-15.7) at the onset of biologic treatment and 11.0 years (range: 2.3-19.5) at the latest followup. Forty-six patients had received corticosteroid and 34 had received more than 1 biologic agent. Patient median height expressed as SD score (SDS) was 0.31 (range: -2.47 to 5.46$)$ at disease onset, -0.24 ( -3.63 to 2.90$)$ at biologic therapy onset $(\mathrm{p}<0.0001)$, and $-0.15(-4.95$ to 3.52$)$ at the latest followup $(\mathrm{p}=$ 0.171 compared to biologic treatment onset). Patients who required several biologics and systemic patients had a significantly lower growth velocity after the onset of biologic treatment. At the latest followup, $18 \%$ of our study group had low growth velocities and $19 \%$ were below -2SD or shorter than genetically programmed.

Conclusion. In a subset of patients, particularly systemic JIA patients and patients who required more than 1 biologic, biologic therapy may be insufficient to restore normal growth velocity. (First Release Dec 1 2013; J Rheumatol 2014;41:128-35; doi:10.3899/jrheum.130311)
\end{abstract}

Key Indexing Terms:

JUVENILE ARTHRITIS BIOLOGIC TREATMENT

\section{SYSTEMIC JUVENILE ARTHRITIS}

\section{CYTOKINE} GROWTH
From the François Rabelais University, Clocheville Pediatric Hospital, Department of General Pediatrics; Pediatric Department, Centre Hospitalier Régional Universitaire (CHRU) Tours, Tours; Pediatric Immunology, Hematology and Rheumatology Unit, Pediatric Endocrinology, Biostatistics and Medical Informatics, Hôpital Necker-Enfants Malades, Assistance Publique-Hôpitaux de Paris (APHP); Université Paris Descartes, Paris, France; University Hospital Gasthuisberg, Pediatric Rheumatology, Leuven, Belgium.

Supported by an educational grant from Pfizer SAS.

Drs. M. Polak and P. Quartier contributed equally to this work.

F. Uettwiller, MD, François Rabelais University, Pediatric Department, CHRU Tours; J. Perlbarg, MD, Biostatistics and Medical Informatics, Hôpital Necker-Enfants Malades, APHP, Université Paris Descartes; G. Pinto, MD, Pediatric Endocrinology, Hôpital Necker-Enfants Malades, APHP, Université Paris Descartes; B. Bader-Meunier, MD; R. Mouy, MD; S. Compeyrot-Lacassagne, MD; I. Melki, MD; Pediatric Immunology, Hematology and Rheumatology Unit, Hôpital Necker-Enfants Malades, APHP, Université Paris Descartes; C. Wouters, MD, PhD, Pediatric Rheumatology, University Hospital Gasthuisberg; A.M. Prieur, MD; P. Landais, MD, PhD, Pediatric Immunology, Hematology and Rheumatology Unit, Hôpital Necker-Enfants Malades, APHP, Université Paris Descartes; M. Polak, MD, PhD, Pediatric Endocrinology, Hôpital Necker-Enfants Malades, APHP, Université Paris Descartes; P. Ouartier, $M D$, Pediatric Immunology, Hematology and Rheumatology Unit, Hôpital Necker-Enfants Malades, APHP, Université Paris Descartes and IMAGINE Institute.

Address correspondence to Dr. P. Quartier, Pediatric Immunology, Hematology and Rheumatology Unit, Pediatric Endocrinology Unit, Hôpital Necker Enfants Malades, 149 rue de Sèvres, 75015 Paris, France. E-mail: pierre.quartier@nck.aphp.fr, michel.polak@nck.aphp.fr Accepted for publication September 12, 2013.
Juvenile idiopathic arthritis (JIA) is a heterogeneous group of diseases characterized by arthritis of unknown etiology starting before the age of 16 years and lasting for more than 6 weeks ${ }^{1}$. The prevalence of JIA has been estimated to be between 16 and 150 per 100,000 children $^{2}$. JIA may be responsible for pain, joint destruction, functional impairment, and in some patients, short stature in adulthood $3,4,5$. According to the most recent classification (revised in 2001), there are 7 JIA subtypes: systemic-onset JIA (SJIA), characterized by the association of systemic features that include a spiking fever and arthritis; rheumatoid factor (RF)-positive polyarthritis; RF-negative polyarthritis; oligoarthritis, characterized by arthritis affecting $<5$ joints during the first 6 months of the disease; enthesitis-related arthritis; psoriatic arthritis; and undifferentiated arthritis ${ }^{1}$.

In the most severe cases, and especially in children with SJIA, the combination of chronic inflammation and corticosteroid treatment can cause severe growth retardation. Conventional disease-modifying antirheumatic agents (DMARD), such as methotrexate (MTX), have been reported to improve JIA patient growth but their effect is 
insufficient in many cases 6,7 . Growth hormone (GH) therapy has been shown to improve and often normalize growth velocity in JIA patients who required long-lasting corticosteroid treatment $^{8,9}$. However, GH therapy remains experimental for this indication.

Biologic treatments have been used in patients with JIA for more than 12 years ${ }^{10,11,12}$. In addition to their powerful effects against joint inflammation and the possible prevention of joint erosion, they may suppress systemic inflammation and may have a corticosteroid-sparing effect in many cases ${ }^{10,13,14}$. Some recent reports indicated that anti-tumor necrosis factor- $\alpha$ (anti-TNF) treatments were associated with growth velocity improvement in patients with $\mathrm{JIA}^{15,16,17}$. In these studies, however, only a small proportion of the patients had SJIA, which is associated with severe systemic inflammation and high corticosteroid requirements, and hence carries the highest risk of growth failure $^{18}$. In addition, patient target height was not documented.

In our study, we assessed height and changes in the height SD scores at disease onset, at the onset of biologic therapy, and at the last followup visit in a cohort of JIA children. All patients were prepubertal or in early puberty when biologic treatment began and were followed for at least 6 months afterward. We conducted this study in a referral pediatric rheumatology center where hundreds of patients with JIA are followed, including a high proportion of patients with SJIA. By taking into account the target height of these patients, our aim was to better assess the effect of biologics on growth in patients with JIA and to analyze the proportion of patients in whom persistent growth impairment might justify $\mathrm{GH}$ treatment. We also sought to determine whether the height SD at the latest followup was influenced by JIA subtype, by comparing patients with SJIA to other patients with JIA, by the presence of corticosteroid treatment, by the requirement of $>1$ biologic during the followup, and by achieving inactive disease at the latest followup.

\section{MATERIALS AND METHODS}

Inclusion criteria. Patients were required to fulfill the International League of Associations for Rheumatology (ILAR) criteria for JIA ${ }^{1}$, to be under biologic therapy for at least 6 months so that it would be possible to assess changes in height SD score (SDS), and to be prepubertal or early pubertal at biologic treatment onset. We included all of the patients who met these criteria and were cared for at the French National Reference Center for Juvenile Arthritis at the Necker-Enfants Malades Hospital, Paris, France, between May and October 2010.

As documented in the patient notes, the parents and patients (when old enough) were informed and agreed that patient data could be recorded in a database built for patients with rare diseases, the CEMARA platform ${ }^{19}$. This included an agreement from the French "Commission Nationale Informatique et Libertés". In accordance with the French rules, no written informed consent was requested for this retrospective study.

Exclusion criteria. Patients who were postpubertal (Tanner staging $>3)^{20}$ at biologic therapy onset and patients with a joint deformity that would not allow proper height assessment were not eligible for the study. Patients with an associated medical condition that could modify their growth and patients who were receiving or had received GH therapy were excluded. Patients were also excluded if it was not possible to retrospectively collect enough data to properly assess their growth.

Data collection. Patient notes were reviewed in detail by one of the authors (FU) who, along with a reference pediatric rheumatologist (PQ, BBM, RM, or $\mathrm{CW}$ ), also saw the patients and their parents on one or several occurrences during the 6-month inclusion period.

The following data were collected: height and weight at birth; height and weight at each outpatient clinic; pubertal stage at biologic treatment onset and at the last followup, according to Tanner classification; mother's and father's heights; patient JIA subset, according to the ILAR classification; presence/absence of uveitis; age at disease onset; and any other medical problems and their treatments. Age at disease onset was defined by patient's age at the first clinical symptom (joint pain or limitation, swollen joint, uveitis, or systemic symptoms). According to Wallace criteria, we consider active disease in the form of 1 or more of the following: persistent active arthritis; disease activity that was determined by the physician to be above $10 / 100$ on a visual analog scale; clinical systemic features, such as fever or pericarditis; active uveitis; and/or an elevated erythrocyte sedimentation rate or serum level of C-reactive protein ${ }^{21}$. Data were also collected regarding any previous or ongoing treatments, including the dose and duration of any corticosteroids, nonbiologic DMARD, biologics, GH, age at biologic therapy onset, number and type of biologics, and the dose and duration of each biologic agent.

Data analyses. Height and weight measurements were performed by a pediatrician. Patient height and weight measurements were recorded using the growth chart published by Sempé, et $a l^{22}$. Patient target height was calculated using Tanner's formula ${ }^{23,24}$. Growth velocity was defined as the change in height SDS during the followup. A positive value indicated catchup growth and a negative value indicated impaired growth. Decreased growth velocity was defined as a difference between the height SDS calculated at 2 consecutive measurements that was $<-0.5$. Height SDS were calculated at 3 different times: at disease onset, at initiation of biologic treatment, and at the latest followup. Height SDS corrected for target height was calculated using an auxological data treatment software (KIGS 5). Change in the height SDS before the onset of biologic therapy and during the interval between biologic therapy onset and the latest followup were also calculated using reference data for the chronological age from the French population ${ }^{22}$

Descriptive summary statistics ( $\mathrm{n}$, mean, SD, median, interquartile range, minimum, and maximum) were used to summarize continuous variables and percentages for discrete variables. Means were compared using a sample t test, Wilcoxon test, or ANOVA. Categorical data were analyzed using the chi-square test or Fisher's exact test, in nonpaired data.

Change in the height SDS was compared using paired samples $t$ test. Correlations between change in the height SD scores and disease-related continuous variables (age at disease onset, disease duration prior to biologic treatments, duration of corticosteroid treatment, or corticosteroid doses in $\mathrm{mg} / \mathrm{m}^{2}$ ) were tested using Spearman's correlation test. Associations between changes in the height SDS and discrete variables were evaluated using chi-square or Fisher's exact tests. A univariate and a multivariate analysis of the association between independent variables and change in the height SDS between the onset of the treatment and the end of the followup was performed using multivariate linear regression models with a stepwise procedure. For multivariate analysis, we selected all variables associated to change in the height SDS with $\mathrm{p}$ value $<0.20$ in univariate analysis. All tests were 2-sided. Analyses were performed using R statistical software (www.r-project.org/).

\section{RESULTS}

Among the 780 patients with JIA followed in our center during the 6-month inclusion period, 190 children were taking biologic treatment. Ninety of these patients were not

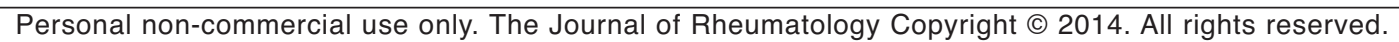


included: 21 had no followup, 9 had incomplete notes, 7 had another disease that could have affected their growth, 4 were in a wheelchair, 31 had a Tanner stage value of $>3$ at biologic treatment initiation, 5 started a biologic treatment for $<6$ months, and 13 were taking GH treatment (Figure 1). At the latest followup, none of the patients had a pubertal delay (defined as no breast development after age of 13 years, or no testis growth after age of 14 years for boys).

The main characteristics of the patients at biologic treatment onset are listed in Table 1. The indications for biologic therapy were active polyarthritis, despite MTX treatment; or severe SJIA or severe uveitis, despite local steroid therapy and MTX, and were in accordance with the practices of the National Reference Center.

The median duration of biologic therapy at the latest followup was 2.92 years (range: 0.59 to $10.17 \mathrm{yrs}$ ). Thirty-five patients had $<2$ years of biologic therapy at the latest followup and 11 patients had $<1$ year. The mean number of biologics per patient was 1.49. Thirty-four patients had received $>1$ biologic and 13 of them had received $>2$ biologics. Fifty-one patients had received anti-TNF treatment (etanercept, adalimumab, or infliximab); 28 had received an anti-interleukin 1 (IL-1) treatment (7 patients received anakinra first, then canakinumab; 3 patients received only canakinumab); 12 had received the

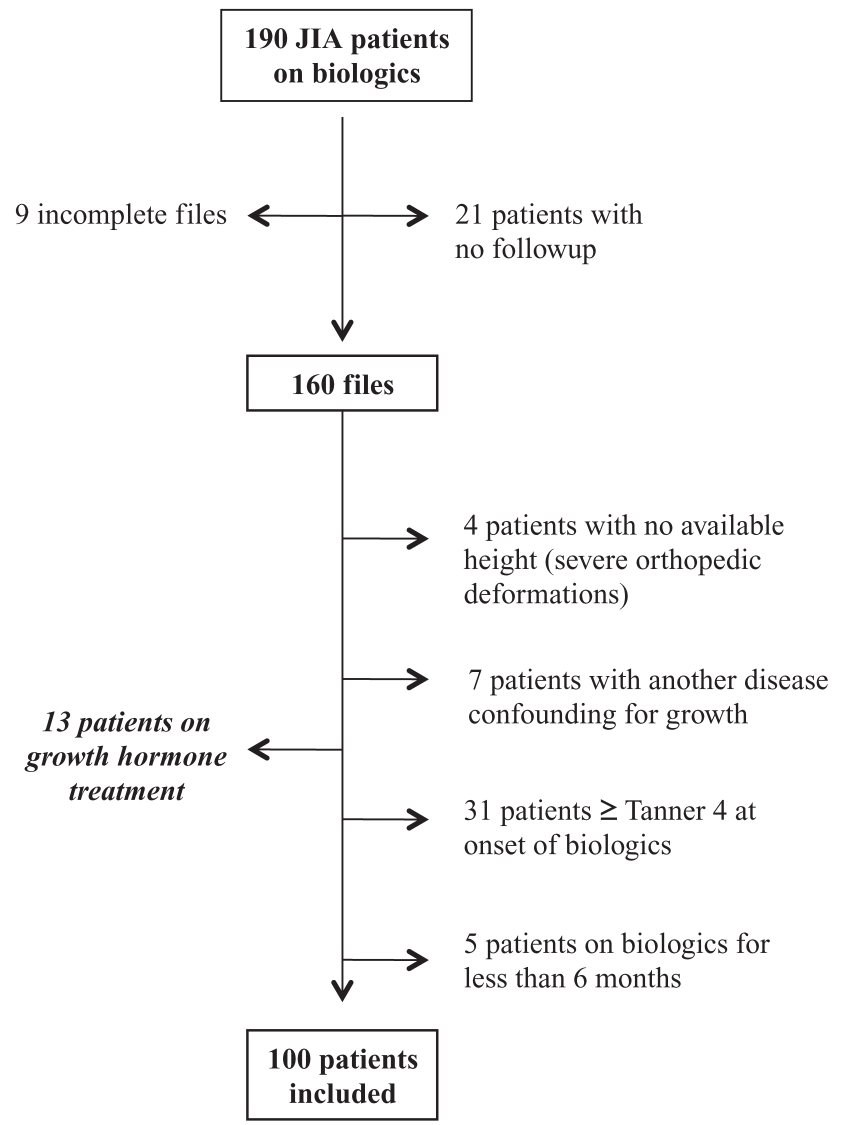

Figure 1. The patient selection process. JIA: juvenile idiopathic arthritis.
Table 1. Main patient characteristics at biologic treatment onset. All values are median value.

\begin{tabular}{|c|c|}
\hline No. patients, sex ratio (male/female) & $100 ; 33 / 67$ \\
\hline \multicolumn{2}{|l|}{ Type of JIA, no. patients } \\
\hline Systemic-onset & 29 \\
\hline Polyarthritis (RF+/RF-) & $36(3 / 33)$ \\
\hline Oligoarthritis (persistent/extended) & $27(9 / 18)$ \\
\hline Enthesitis-related JIA (HLA-B27士) & $8(5 / 3)$ \\
\hline Age at disease onset, yrs (range) & $4.26(0.69$ to 13.72$)$ \\
\hline Age at biologic treatment onset, yrs (range) & $7.11(1.58$ to 15.68$)$ \\
\hline JIA duration, yrs (range) & $1.78(0.18$ to 11.14$)$ \\
\hline Height, cm (range) & $119(80$ to 177.5$)$ \\
\hline Height, SD (range) & $-0.24(-3.63 \text { to } 2.9)^{*}$ \\
\hline Active disease (no. patients) & 45 \\
\hline Elevated $(>1 / 40)$ antinuclear antibodies (no. patien & ats) \\
\hline Uveitis (no. patients) & 22 \\
\hline \multicolumn{2}{|l|}{ Previous steroid treatments } \\
\hline No. patients & 46 \\
\hline Age at onset, yrs (range) & $5.0(0.9$ to 13.4$)$ \\
\hline \multicolumn{2}{|l|}{ Previous nonbiologic DMARD } \\
\hline No. patients & 72 \\
\hline Age at onset, yrs (range) & $5.9(1.2$ to 15.5$)$ \\
\hline
\end{tabular}

anti-IL-6 receptor antibody tocilizumab; and 9 had received CTLA-4Ig (abatacept). Biologic treatment was combined with MTX in 51 patients. From the onset of biologic treatment to the latest followup, 5 patients had to start steroids. At the latest followup, 45 patients had active disease.

The distribution of height SDS at disease onset, biologic treatment onset, and at the latest followup is shown in Figure 2. All patients had a normal body mass index at inclusion.

The median height SDS of the patients were 0.31 (range -2.47 to 5.46) at disease onset (mean height SDS: 0.41 SD \pm 1.13 ) and -0.24 (range -3.63 to 2.90 ) at biologic therapy onset, which was significantly lower $(p<0.0001)$ than the score at disease onset. The median height SDS was -0.15 (range -4.95 to 3.52 ) at the latest followup, which was not significantly different from the SDS at biologic treatment onset $(\mathrm{p}=0.17)$.

Median height SDS corrected for target height were 0.14 (range -3.27 to 4.25 ) at disease onset, -0.31 (range -4.48 to 2.3 ) at biologic therapy onset ( $\mathrm{p}<0.0001$ ), and -0.35 (range -6.00 to 2.69 ) at the latest followup ( $\mathrm{p}=0.61$ compared to the score at the onset of biologic treatment). Among 100 patients, 43 had low growth velocities (defined as $\Delta \mathrm{SD}$ scores $<-0.5$ ) before the onset of biologic treatment (Figure $3)$. From biologic therapy onset to the latest followup, growth velocity remained low for 13 patients. In addition, among 24 patients who had maintained a normal growth velocity before biologic treatment onset, 5 had lower growth velocities afterwards. Eighteen patients (18\% of our study

Personal non-commercial use only. The Journal of Rheumatology Copyright @ 2014 . All rights reserved. 


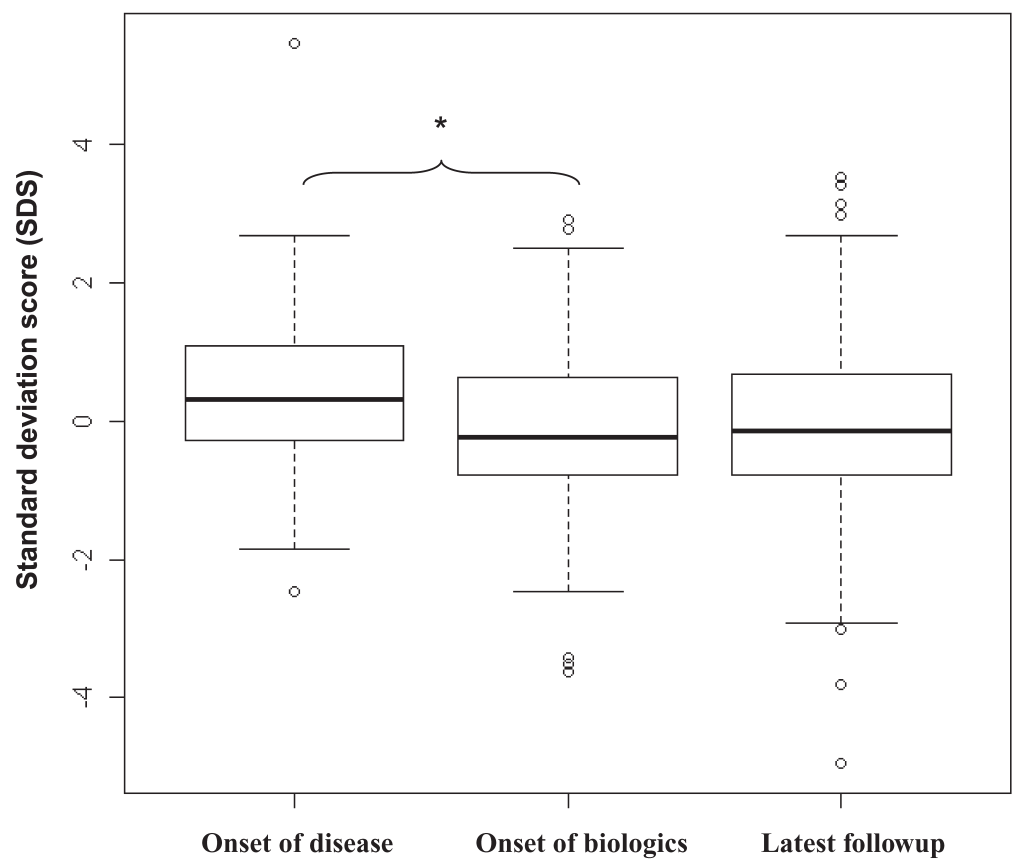

Figure 2. Patients' height distribution. Height distribution is expressed as an SD score (SDS) at disease onset, biologic treatment onset, and the latest followup. Each diagram represents the minimum, 25th percentile, median, 75th percentile, and maximum of the SDS. * Significant difference $(\mathrm{p}<0.0001)$.

\section{Before biologic treatment onset}

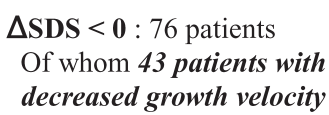
$(\triangle \mathrm{SDS}<-0,5)$

\section{On biologics}

$\triangle \mathbf{S D S}<\mathbf{0}: 35$ patients Of whom 13 patients with decreased growth velocity $(\triangle \mathrm{SDS}<-0.5)$

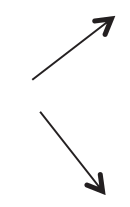

$\Delta$ SDS $\geq 0: 41$ patients Of whom 12 patients with increased growth velocity $(\Delta \mathrm{SDS}>0.5)$

$\triangle$ SDS $\geq 0: 24$ patients

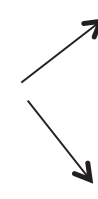

$\Delta$ SDS $\geq 0: 13$ patients

$\Delta$ SDS $<0: 11$ patients Of whom 5 patients with decreased growth velocity $(\Delta \mathrm{SDS}<-0.5)$

Figure 3. Growth velocity under biologic treatment. The change in growth velocity from disease onset to biologic treatment onset is shown in relation to the prior growth course; $\triangle \mathrm{SDS}$ (SD score) represents the growth velocity, expressed as a decelerating growth velocity if $\Delta$ SDS $<-0.5$ or an accelerating growth velocity if $\Delta \mathrm{SDS}>0.5$. While taking biologics, 18 patients still had a decreased growth velocity.

group), thus, had low growth velocities after the onset of biologic treatment. We analyzed changes in the height SDS (height difference expressed in SDS) between the onset of biologic treatment and the latest followup according to the JIA subtype, steroids usage, the number of biologics, and disease activity at the latest followup (Figure 4). In the multivariate analysis, patients who had been treated with > 1 biologic agent and patients with SJIA had significantly lower changes in the height SDS on biologic treatment than other patients ( $\mathrm{p}=0.01$ and $\mathrm{p}=0.04$, respectively). Although steroid usage and active disease at the latest followup tended to be associated in univariate analysis ( $\mathrm{p}<$ 0.20 ) with lower changes in the height SDS on biologics, none of these associations were statistically significant after adjustment of the other dependent variables.

We also analyzed height SD at the onset of biologic treatment (SD corr TH): 15 patients were below -2SD. After the correction for target height (SD corr $\mathrm{TH}$ ), 11 patients already had scores below -2SD. Three of them had polyarticular JIA (of whom 1 had uveitis) and 8 had systemic JIA; 9 had received corticosteroids (1 polyarticular and 8 systemics); and 8 had inactive disease and 3 had active disease (all were systemic) at the last followup. These children had been treated with an average of 1.7 biologics and 6 had been treated with $>1$ biologic. After the onset of biologic treatment, 4 of these patients maintained low growth velocity up to the latest followup (defined as a $\triangle \mathrm{SD}$ score of $<-0.5$; Appendix 1). 

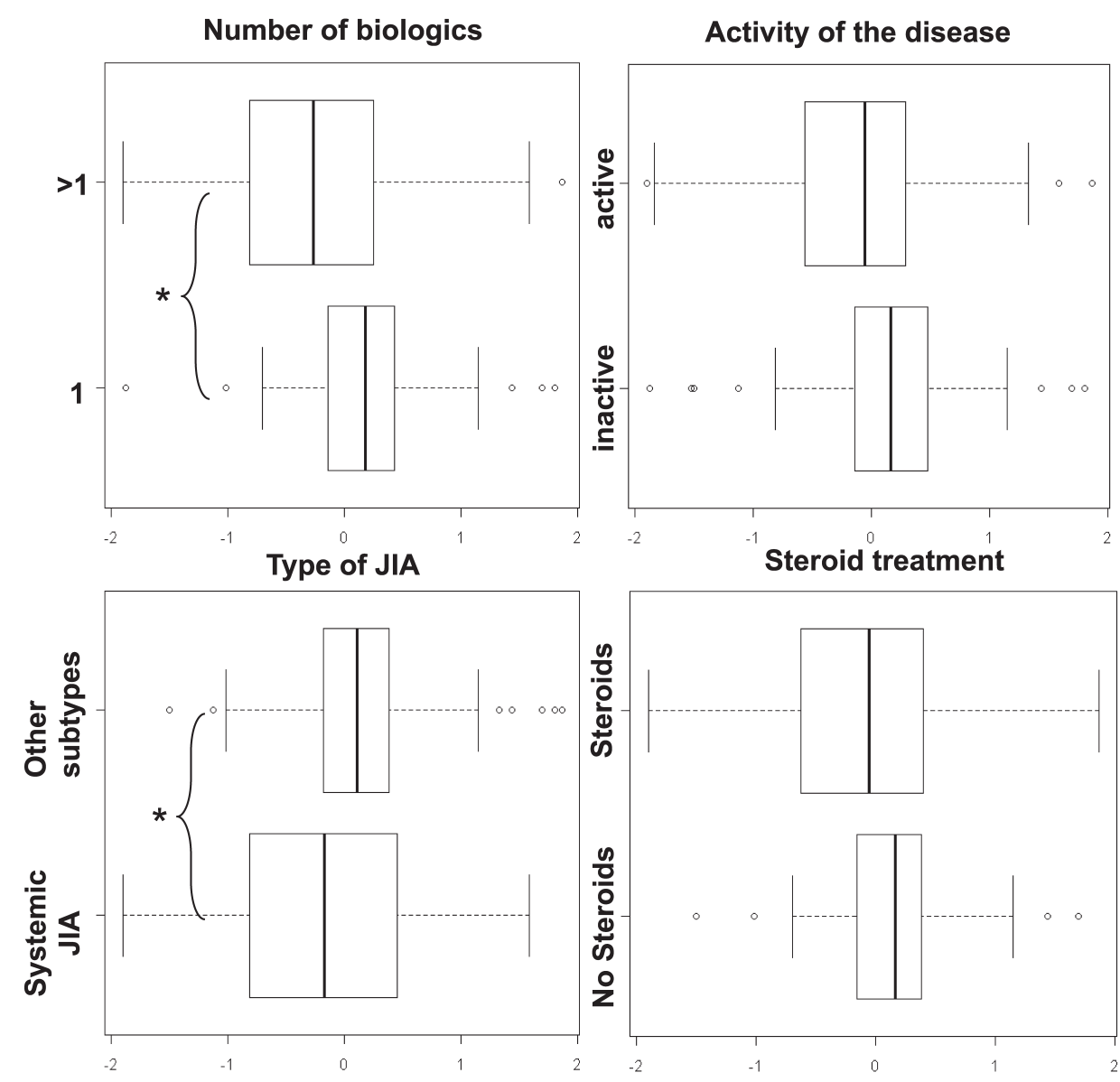

\section{Difference of height SDS between onset of biologics and the latest followup}

Figure 4. Change in height SD score (SDS) according to JIA subtype, disease activity, steroid treatment, and the number of biologics. The change in height is expressed as the difference between the SDS at the onset of biologic treatment and the SDS at the latest followup. Each diagram represents the minimum, 25th percentile, median, 75th percentile, and maximum of the SDS. * Significant difference $(\mathrm{p}<0.05)$. JIA: juvenile idiopathic arthritis.

Finally, at the latest followup, 10 patients had a growth retardation (height $<-2$ SDS) and 1 patient had a height below -2 SDS corrected for target height, but his height was -0.3 SDS not corrected for target height (Table 2). At disease onset, growth retardation $<-2$ SDS was already documented in 1 patient. Compared to the global population of our study, these 11 patients had the same JIA duration before treatment (median of $1.6 \mathrm{yrs}$ vs $1.8 \mathrm{yrs}$ ), the same disease duration (5.4 yrs vs $5.3 \mathrm{yrs}$ ), and the same time under biologic treatment ( $2.8 \mathrm{yrs}$ vs $2.9 \mathrm{yrs}$ ), but their disease had started earlier ( $2.1 \mathrm{yrs}$ vs $4.3 \mathrm{yrs}$ ). Eight other children had height SDS that were $<-1.5$ of their target height at the latest followup. These patients were shorter than genetically programmed, as target height $\pm 1.5 \mathrm{SD}$ is the generally accepted distribution ${ }^{23}$. The characteristics of these patients are described in Table 2. Nineteen patients ( $19 \%$ of our study group), thus, were below -2 SD or shorter than genetically programmed at the last followup.

\section{DISCUSSION}

In a cohort of 100 prepubertal or early pubertal children with JIA treated with biologics (but not with $\mathrm{GH}$ ) and followed in a single reference pediatric rheumatology center, we were able to document a low mean growth velocity at the initiation of biologic therapy and an improvement under biologic treatment. However, in most patients who had developed growth retardation before the onset of biologic therapy, it persisted at the latest followup.

Our cohort of patients had some peculiar characteristics that should be taken into account when interpreting these results. First, a relatively high percentage of the patients had SJIA, a JIA subset that is classically associated with a higher risk of growth failure 25,26 . In our study, SJIA patients differed significantly from the other patients with respect to their changes in the height SDS under biologic therapy. The larger availability of more active treatment, particularly anti-IL-1 and anti-IL-6 treatments in patients with 
Table 2. Patients with growth retardation (height $<-2 \mathrm{SD}$ or height correction for target height $(\mathrm{TH})<-1.5 \mathrm{SD}$ ) at the latest followup.

\begin{tabular}{|c|c|c|c|c|c|c|c|c|}
\hline $\begin{array}{l}\text { Height at Disease } \\
\text { Onset, SD; TH } \\
\text { corr SD }\end{array}$ & $\begin{array}{c}\text { Height at Biologic } \\
\text { Onset, SD; TH } \\
\text { corr SD }\end{array}$ & $\begin{array}{l}\text { Height at the Latest } \\
\text { Followup, SD; } \\
\text { TH corr SD }\end{array}$ & $\begin{array}{l}\text { Type of JIA } \\
\text { (Active = A; } \\
\text { Inactive = I) }\end{array}$ & $\begin{array}{c}\text { JIA Duration at } \\
\text { Biologic Onset, } \\
\text { yrs }\end{array}$ & $\begin{array}{l}\text { JIA Duration at } \\
\text { the Latest } \\
\text { Followup, yrs }\end{array}$ & $\begin{array}{c}\text { Steroids* } \\
\mathrm{g}^{-2} ; \mathrm{yrs}\end{array}$ & $\begin{array}{c}\text { Number of } \\
\text { Biologics }\end{array}$ & $\begin{array}{c}\text { Age (yrs); } \\
\text { Tanner at } \\
\text { Last Followup }\end{array}$ \\
\hline $0.6 ;-0.5$ & $-3.4 ;-4.5$ & $-5.0 ;-6.0$ & Systemic (A) & 6.1 & 10.2 & $36.4 ; 8.3$ & 3 & $11.7 ; 1$ \\
\hline$-1.2 ; 0.6$ & $-3.6 ;-1.9$ & $-3.8 ;-2.1$ & Systemic (A) & 0.8 & 2.2 & $13.4 ; 1.7$ & 2 & $13.8 ; 5$ \\
\hline$-0.6 ;-1.3$ & $-1.1 ;-1.8$ & $-3.0 ;-3.7$ & Systemic (A) & 0.7 & 5.3 & $31.2 ; 5.2$ & 4 & $7.4 ; 1$ \\
\hline$-0.7 ;-0.2$ & $-1.3 ;-0.8$ & $-2.4 ;-1.9$ & Polyarticular (I) & 1.5 & 11.3 & $23.8 ; 10.7$ & 2 & $15.1 ; 1$ \\
\hline$-0.4 ;-1.4$ & $-1.6 ;-2.6$ & $-2.4 ;-3.4$ & Systemic (I) & 1.6 & 5.4 & $21.9 ; 5.4$ & 2 & $6.9 ; 1$ \\
\hline$-0.5 ; 0.2$ & $-0.7 ; 0.0$ & $-2.2 ;-1.5$ & Polyarticular (A) & 0.9 & 9.1 & $0 ; 0$ & 3 & $11 ; 1$ \\
\hline$-2.5 ;-2.1$ & $-2.5 ;-2.1$ & $-2.2 ;-1.8$ & Polyarticular (I) & 2.4 & 3.7 & $0 ; 0$ & 1 & $5.4 ; 1$ \\
\hline $0.9 ;-0.8$ & $-0.2 ;-1.9$ & $-2.0 ;-3.7$ & Systemic (A) & 0.6 & 3.4 & $7.2 ; 1.9$ & 3 & $6.3 ; 1$ \\
\hline \multicolumn{9}{|c|}{ Patients with height $\geq-2 \mathrm{SD}$ but corrected for target height $<-1.5 \mathrm{SD}$ at last followup } \\
\hline$-0.7 ;-2.3$ & $-0.8 ;-2.3$ & $-0.1 ;-1.7$ & Polyarticular (I) & 0.6 & 3.9 & $0 ; 0$ & 2 & $5.1 ; 1$ \\
\hline $0.1 ;-1.4$ & $-0.1 ;-1.5$ & $-0.2 ;-1.7$ & ERA (I) & 1.4 & 3.2 & $2.9 ; 0.8$ & 1 & $12.3 ; 1$ \\
\hline$-0.2 ;-1.3$ & $-0.3 ;-1.4$ & $-0.6 ;-1.6$ & Polyart. RF+ (I) & 0.3 & 3.2 & $10 ; 2.6$ & 3 & $12.9 ; 3$ \\
\hline$-0.3 ; 0.1$ & $-3.5 ;-3.2$ & $-1.9 ;-1.6$ & Systemic (A) & 3.3 & 5.6 & $28.6 ; 5$ & 3 & $6.3 ; 1$ \\
\hline $0.3 ;-0.7$ & $-0.2 ;-1.2$ & $-0.5 ;-1.5$ & Ext. Oligo (A) & 2.2 & 6.0 & $0 ; 0$ & 4 & $14.3 ; 5$ \\
\hline
\end{tabular}

* The cumulative dose of steroids $\left(\mathrm{g}^{-2}\right)$ was divided by the length of steroids treatment. JIA: juvenile idiopathic arthritis; ERA: enthesitis-related arthritis; RF: rheumatoid factor.

SJIA $^{25,26,27,28,29,30}$ may allow for reducing the effect of systemic disease on growth. Second, patients referred to a referral pediatric rheumatology center are often the most difficult to treat. Although the persistence of active disease at the latest followup was not associated with a significantly worse growth prognosis, a high proportion of our patients had failed to adequately respond to a first biologic agent and their change in the height SDS was significantly lower than normal from the onset of biologic therapy to the latest followup. In addition, there was some heterogeneity regarding the duration of biologic treatment; however, most patients had been receiving biologic treatment more than 2 years at the latest followup.

Previous reports have suggested that anti-TNF treatments, the most widely used biologics, have a significant and positive effect on the growth of patients with JIA $15,17,31,32$. A study of a large U.S. cohort of 594 patients treated with the soluble TNF- $\alpha$ receptor etanercept documented a gain of 4.8 percentiles after 3 years of treatment for children below Tanner stage $4^{16}$. This height gain, albeit statistically significant, was clinically modest. However, the population was heterogeneous regarding age at biologic treatment onset and some of the children were already pubertal. In another report, 51 of 71 children treated with anti-TNF agents experienced altered growth before starting biologic therapy and these patients gained an average of $0.45 \mathrm{SD}$ after 2 years. Moreover, different subtypes of JIA were followed: $18 \%$ of these patients did not respond in terms of height development to etanercept treatment and that was the group of patients with severe and systemic JIA ${ }^{32}$. Two other studies of smaller numbers of patients also indicated similarly encouraging results of anti-TNF treatment in terms of growth velocity improvement and height gain, compared to the pretherapeutic period ${ }^{15,17}$. Nevertheless, another study of 52 patients treated with etanercept found that prepubertal patients had no significant height gain, despite subgroup analyses that showed a trend toward amelioration ${ }^{31}$. In our study, the high proportions of patients with SJIA and patients with difficult-to-treat JIA may account for the high number of patients who retained a problematic height prognosis. Indeed, our cohort contained $29 \%$ SJIA children versus levels of $10 \%$ or less in prior studies. In addition, $45 \%$ of our children had active disease at the latest followup and a high proportion had been successively treated with several biologics including non-anti-TNF agents. Finally, we included only nonpubertal, prepubertal, or early pubertal children and took into account patient target height, which also increased the proportion of patients in our study who were diagnosed with growth disturbance compared to previous studies. As the great majority of the subjects had no significant pubertal delay, we do not believe that negative value for height SDS could be due to late puberty. Nevertheless, our patients' growth was better than that reported for patients with JIA who received no biologic treatment, whose final height was below -2 SD in $41 \%$ of the patients with SJIA and $11 \%$ of the patients with polyarticular JIA ${ }^{5}$.

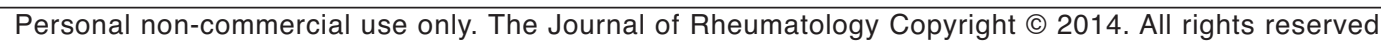


The absence of a significant association between steroid usage and the growth potential of patients taking biologics in our study was in line with a report by Giannini, et $a l^{16}$. In contrast, Tynjäla, et al reported that steroid treatment and disease activity impaired the growth of patients taking biologics $^{32}$. Steroid treatment may help and hinder the growth of patients with JIA. Its effect in reducing systemic inflammation may be positive in some patients, particularly those with SJIA in whom high systemic inflammation and high IL-6 levels can affect growth ${ }^{33,34}$. In some children, this effect may counterbalance the well-known negative effect on growth of long-lasting steroid therapy.

Because the growth potential of the patients in our study and in others ${ }^{18,35}$ was already altered before the onset of biologic treatment, earlier treatment with biologics might be the best way to allow patients with JIA to reach their target height. In this regard, however, the median disease duration at biologic treatment onset $(16 \mathrm{mos})$ was relatively short in our study compared to that of previous studies. It remains to be determined whether earlier referral of patients with severe JIA to tertiary care centers or earlier introduction of biologic treatment could improve the growth prognosis of these patients.

Biologic therapy has a positive effect on changes in the height SDS in patients with JIA. However, such therapy might be insufficient to restore normal growth in a subset of patients, particularly in those who do not adequately respond to their first biologic agent. Early initiation of biologic therapy and selecting an optimal first biologic agent may be important options for improving the final height of patients with JIA.

\section{ACKNOWLEDGMENT}

We thank Prof. Paul Czernichow for his longstanding help and support in the studies of growth in children with JIA.

\section{REFERENCES}

1. Petty RE, Southwood TR, Manners P, Baum J, Glass DN, Goldenberg J, et al. International League of Associations for Rheumatology classification of juvenile idiopathic arthritis: second revision, Edmonton, 2001. J Rheumatol 2004;31:390-2.

2. Ravelli A, Martini A. Juvenile idiopathic arthritis. Lancet 2007;369:767-78.

3. Seid M, Opipari L, Huang B, Brunner HI, Lovell DJ. Disease control and health-related quality of life in juvenile idiopathic arthritis. Arthritis Rheum 2009;61:393-9.

4. Polito C, Strano CG, Olivieri AN, Alessio M, Iammarrone CS, Todisco N, et al. Growth retardation in non-steroid treated juvenile rheumatoid arthritis. Scand J Rheumatol 1997;26:99-103.

5. Minden K. Adult outcomes of patients with juvenile idiopathic arthritis. Horm Res 2009;72 Suppl 1:20-5.

6. Chedeville G, Quartier P, Miranda M, Brauner R, Prieur AM. Improvements in growth parameters in children with juvenile idiopathic arthritis associated with the effect of methotrexate on disease activity. Joint Bone Spine 2005;72:392-6.

APPENDIX 1. Patients below a -2 SD score (SDS) corrected for target height at onset of biologic. Each line represents the change in the height SDS corrected for target height, per patient, at the onset of disease, at the onset of biologic treatment, and at the last followup.

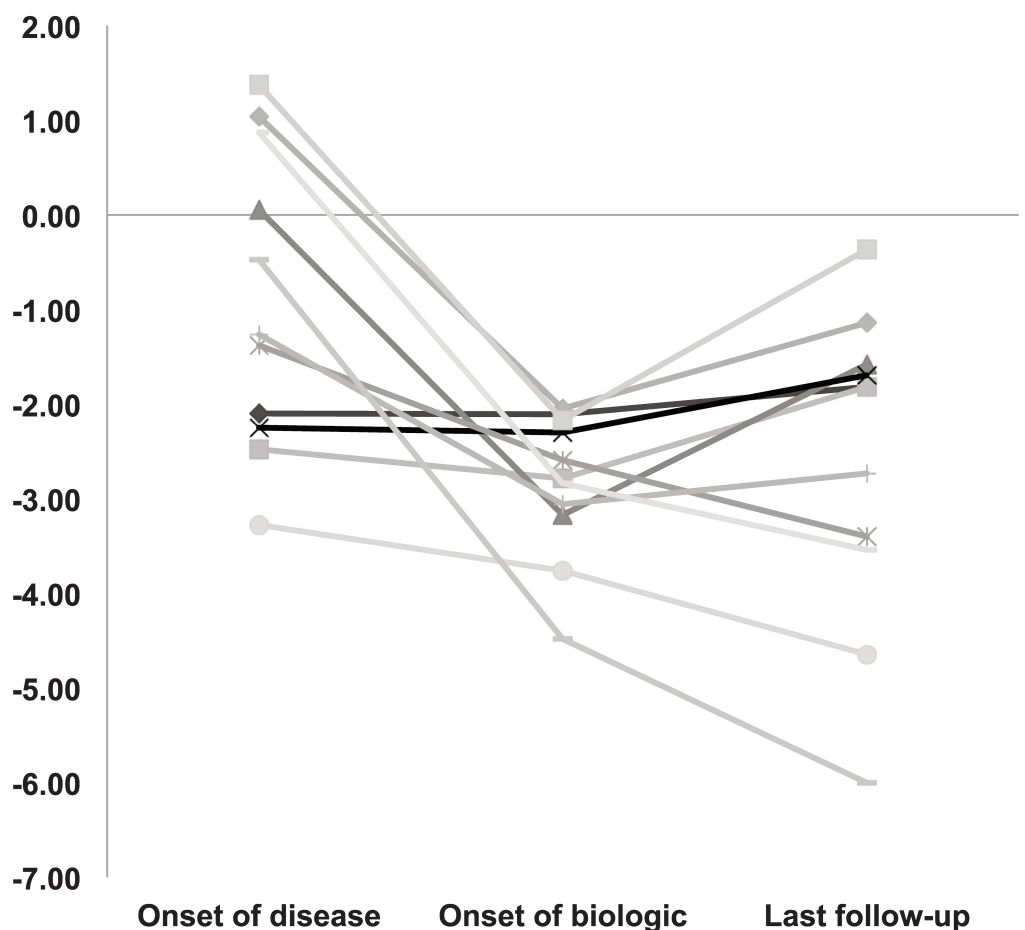


7. Simon D, Lucidarme N, Prieur AM, Ruiz JC, Czernichow P. Linear growth in children suffering from juvenile idiopathic arthritis requiring steroid therapy: natural history and effects of growth hormone treatment on linear growth. J Pediatr Endocrinol Metab 2001;14 Suppl 6:1483-6.

8. Simon D, Prieur AM, Quartier P, Charles Ruiz J, Czernichow P Early recombinant human growth hormone treatment in glucocorticoid-treated children with juvenile idiopathic arthritis: a 3-year randomized study. J Clin Endocrinol Metab 2007;92:2567-73.

9. Bechtold S, Ripperger P, Dalla Pozza R, Bonfig W, Hafner R, Michels $\mathrm{H}$, et al. Growth hormone increases final height in patients with juvenile idiopathic arthritis: data from a randomized controlled study. J Clin Endocrinol Metab 2007;92:3013-8.

10. Lovell DJ, Reiff A, Ilowite NT, Wallace CA, Chon Y, Lin SL, et al. Safety and efficacy of up to eight years of continuous etanercept therapy in patients with juvenile rheumatoid arthritis. Arthritis Rheum 2008;58:1496-504.

11. Quartier P, Taupin P, Bourdeaut F, Lemelle I, Pillet P, Bost M, et al. Efficacy of etanercept for the treatment of juvenile idiopathic arthritis according to the onset type. Arthritis Rheum 2003; 48:1093-101.

12. Horneff G, Schmeling H, Biedermann T, Foeldvari I, Ganser G, Girschick HJ, et al. The German etanercept registry for treatment of juvenile idiopathic arthritis. Ann Rheum Dis 2004;63:1638-44.

13. Ruperto N, Lovell DJ, Cuttica R, Woo P, Meiorin S, Wouters C, et al. Long-term efficacy and safety of infliximab plus methotrexate for the treatment of polyarticular-course juvenile rheumatoid arthritis: findings from an open-label treatment extension. Ann Rheum Dis 2010;69:718-22.

14. Ruperto N, Lovell DJ, Quartier P, Paz E, Rubio-Perez N, Silva CA, et al. Long-term safety and efficacy of abatacept in children with juvenile idiopathic arthritis. Arthritis Rheum 2010;62:1792-802.

15. Billiau AD, Loop M, Le PQ, Berthet F, Philippet P, Kasran A, et al. Etanercept improves linear growth and bone mass acquisition in MTX-resistant polyarticular-course juvenile idiopathic arthritis. Rheumatology 2010;49:1550-8.

16. Giannini EH, Ilowite NT, Lovell DJ, Wallace CA, Rabinovich CE, Reiff A, et al. Effects of long-term etanercept treatment on growth in children with selected categories of juvenile idiopathic arthritis. Arthritis Rheum 2010;62:3259-64.

17. Schmeling H, Seliger E, Horneff G. Growth reconstitution in juvenile idiopathic arthritis treated with etanercept. Clin Exp Rheumatol 2003;21:779-84.

18. Simon D, Fernando C, Czernichow P, Prieur AM. Linear growth and final height in patients with systemic juvenile idiopathic arthritis treated with longterm glucocorticoids. J Rheumatol 2002;29:1296-300.

19. Landais P, Messiaen C, Rath A, Le Mignot L, Dufour E, Ben Said $\mathrm{M}$, et al. CEMARA an information system for rare diseases. Stud Health Technol Inform 2010;160:481-5.

20. Tanner JM. Growth at adolescence; with a general consideration of the effects of hereditary and environmental factors upon growth and maturation from birth to maturity. 2nd ed. Oxford: Blackwell Scientific Publications; 1962.

21. Wallace CA, Ravelli A, Huang B, Giannini EH. Preliminary validation of clinical remission criteria using the OMERACT filter for select categories of juvenile idiopathic arthritis. J Rheumatol 2006;33:789-95.
22. Sempé M, Pédron G, Roy-Pernot MP, eds. Auxologie méthode et séquences. Paris: Théraplix; 1979.

23. Tanner JM, Goldstein H, Whitehouse RH. Standards for children's height at ages 2-9 years allowing for heights of parents. Arch Dis Child 1970;45:755-62.

24. Karlberg J, Fryer JG. A method for adjustment of final height for midparental height for Swedish children. Acta Paediatr Scand 1990;79:468-9.

25. Nigrovic PA, Mannion M, Prince FH, Zeft A, Rabinovich CE, van Rossum MA, et al. Anakinra as first-line disease-modifying therapy in systemic juvenile idiopathic arthritis: report of forty-six patients from an international multicenter series. Arthritis Rheum 2011;63:545-55.

26. Ruperto N, Quartier P, Wulffraat N, Woo P, Ravelli A, Mouy R, et al. A phase II, multicenter, open-label study evaluating dosing and preliminary safety and efficacy of canakinumab in systemic juvenile idiopathic arthritis with active systemic features. Arthritis Rheum 2012;64:557-67.

27. Yokota S, Imagawa T, Mori M, Miyamae T, Aihara Y, Takei S, et al. Efficacy and safety of tocilizumab in patients with systemic-onset juvenile idiopathic arthritis: a randomised, double-blind, placebo-controlled, withdrawal phase III trial. Lancet 2008;371:998-1006.

28. Quartier P, Allantaz F, Cimaz R, Pillet P, Messiaen C, Bardin C, et al. A multicentre, randomised, double-blind, placebo-controlled trial with the interleukin-1 receptor antagonist anakinra in patients with systemic-onset juvenile idiopathic arthritis (ANAJIS trial). Ann Rheum Dis 2011;70:747-54.

29. De Benedetti F, Brunner HI, Ruperto N, Kenwright A, Wright S, Calvo I, et al. Randomized trial of tocilizumab in systemic juvenile idiopathic arthritis. N Engl J Med 2012;367:2385-95.

30. Ruperto N, Brunner HI, Quartier P, Constantin T, Wulffraat N, Horneff $\mathrm{G}$, et al. Two randomized trials of canakinumab in systemic juvenile idiopathic arthritis. N Engl J Med 2012;367:2396-406.

31. Vojvodich PF, Hansen JB, Andersson U, Savendahl L, Hagelberg S Etanercept treatment improves longitudinal growth in prepubertal children with juvenile idiopathic arthritis. J Rheumatol 2007;34:2481-5.

32. Tynjala P, Lahdenne P, Vahasalo P, Kautiainen H, Honkanen V. Impact of anti-TNF treatment on growth in severe juvenile idiopathic arthritis. Ann Rheum Dis 2006;65:1044-9.

33. Souza LS, Machado SH, Brenol CV, Brenol JC, Xavier RM. Growth velocity and interleukin 6 concentrations in juvenile idiopathic arthritis. J Rheumatol 2008;35:2265-71.

34. De Benedetti F, Martini A. Cytokines et de retard de croissance au cours des maladies inflammatoires chroniques chez les enfants (French). Cytokines and growth delay during chronic inflammatory diseases in children. Arch Pediatr 1999;6:499-502.

35. Czernichow P. Growth and development abnormalities in children with juvenile idiopathic arthritis: treatment and prevention. Horm Res 2009;72 Suppl 1:1-3. 